Volume 30, 2020

http://journals.sfu.ca/cjsdw

\title{
Article
}

\section{Do This Article}

Meredith Barrett

Rhode Island School of Design

\section{Abstract}

From the multiple theories of experiential learning to discourse on learning styles and preferences, hands-on learning is well known as an important mode of engaging with new ideas and processes. This article runs with this notion by not just sharing interactive activities for training peer tutors but asking readers to participate in them. A narrative and reflective essay, it walks the audience through three exercises, step by step, and explores their impact in the contexts of the author's tutor training program, her 2019 Canadian Writing Center Association Conference workshop, and the article itself. The piece asks whether there is room for more hands-on learning in all of these venues and calls on readers to reflect on their own experiences.

Keywords: Hands-on; interactive; tutor training; multiliteracies

Hello, there. Welcome to my article. I know this voice is probably not what you were expecting, but please, settle in and make yourself comfortable. I'm speaking to you directly because I want to engage you in this article. Not just rhetorically by addressing you in second person, but literally by getting you to participate as you read.

You see, I want to tell you about the session I ran at the 2019 Canadian Writing Center Association Conference in Vancouver, BC. It was called “Wet Feet, Dirty Hands: Preparing Multiliteracy Tutors.” In it, I shared some hands-on activities from my center's tutor education program, and I did it in a hands-on way. My goal was for the workshop to not just communicate the importance of hands-on experience in multiliteracy (and all kinds of) training, but to put that idea into action. 
Volume 30, 2020

http://journals.sfu.ca/cjsdw

I spent at least three quarters of the hour-long workshop leading participants in the hands-on activities I use with my tutors-getting their proverbial feet wet and hands dirty. My choice to go heavy on the interactive was about more than just practicing what I preach; I wanted conferencegoers to leave my session feeling like they could do something they had not done before. I wanted them to feel they could take on multiliteracy tutoring, that they could work more hands-on activities into their own staff meetings. I wanted them to not just think they should do any of these things but feel they could because they had experienced their success and impact themselves. I want the same outcome for you.

So I can't just tell you about my conference session; I have to recreate it. Accomplishing this in a journal article presents a whole new challenge: I want to provide you with the same tactile, kinesthetic, living, breathing experience my tutors have in staff meetings and the conference-goers had in my workshop-but in text format. The task requires something a little bit different. I'm attempting to create an interactive article, some combination of scholarly writing, instruction manual, and choose-your-own-adventure story. I suppose you might just read it through, and I hope you'd gain something from that too, but I really hope you'll take my intentions to heart and join me in this experiment.

Let's start right now. I'm going to direct you through an activity (the first of a few) that I used in tutor training and in my conference session. Follow my instructions in real time; I think that will be more effective than reading ahead and then trying things out later. Please also read all activity instructions aloud, if possible, so you can hear them in the room, instead of just in your head. I'll put all my activity instructions in italics so you can easily jump into action. Ready? Let's dive in.

First, you'll need a partner, so go find a colleague, friend, or willing stranger passing by. It also helps to have a timer, so grab one while you're away from this text.

Okay, now find someplace to stand face to face, about arm's length apart, with room to move around.

Choose which one of you will be the hypnotist and which will be hypnotized. You'll switch roles, so it doesn't matter who goes first.

Who's the hypnotist? Raise your hand. That hand is the thing that will hypnotize your partner. Hold that hand in front of your partner's face. 
Volume 30, 2020

http://journals.sfu.ca/cjsdw

Partner, now you're hypnotized. You have to keep your face in front of that hand, while the hypnotist glides it around (up, down, back, forth, etc.), getting you to move through space and maybe even contort your body. Do this for 60 seconds. Set that timer, so you don't have to count; allow yourself to focus on what's happening and respond to each other.

When the timer goes off, switch roles. New hypnotist, hold your hand in front of your partner's face, set the timer for 60 seconds, and proceed to guide their movements. Hypnotized, keep your face in front of that hand until the timer goes off.

Now, how did that go? Share some immediate thoughts on this experience, even just some adjectives (it's okay if your responses contradict themselves or each other's): First, what was it like to be the hypnotist? And what was it like to be hypnotized?

Discuss how you think this relates to tutoring, building off your own experience as well as the adjectives your partner used to describe it.

This exercise comes from Agosto Boal's Theater of the Oppressed, an approach that uses theater as a means of promoting social and political change by allowing participants to explore and even transform their realities. I first encountered it in Boal's Games for Actors and Non-Actors (2002), but I first witnessed it in the context of tutoring centers at the 2018 Northeast Writing Centers Association conference. Laura Greenfield and the tutors of Hampshire College's Transformative Speaking Center used the exercise as an icebreaker and introduction to their roundtable discussion on assessing antiracist efforts in our centers. At my tutoring center, I used this activity on one of our retreat days, a longer staff meeting at the start of the academic year in which we introduce our shared values as a center. It's a good warm-up, getting everyone present in their bodies and putting them in a common, vulnerable position. It also gets tutors thinking about and prepared for the interpersonal work of tutoring.

Boal's book being a guide for facilitators, it provides much more detailed instructions than I do, from the position of the hand and face to the speed and extent of the movements being created. These directions take into account the sensitive nature of such an intimate interpersonal experience. I intentionally keep the instructions simple (even vague), because I want participants to have to embody that sensitivity, to figure it out for themselves: to lead someone too fast at first and adjust based on their body language; to learn how they feel when they are in control of someone's body and when 
Volume 30, 2020

http://journals.sfu.ca/cjsdw

someone else controls theirs; to recognize that not everyone's range of movement is the same. As soon as it's over, everyone starts to laugh and chat: "I couldn't figure out what this meant." "I didn't mean to make you do that." This natural chatter is a good starting point for more structured conversation.

My follow-up questions are inspired by Greenfield's. In her roundtable, my tutor meeting, and the CWCA workshop, discussion prompts expanded that initial unpacking into deeper analysis of the non-verbal and verbal communication in tutoring sessions. Participants talked about how important it is to check in with tutees, but also to build rapport and trust so students can be honest about what isn't working for them. When I asked for adjectives for each role, responses varied wildly. The power of the hypnotist role felt fun and exciting to some, while others felt uncomfortable or overwhelmed with empathy for their partner. The hypnotized role made some feel vulnerable, resistant or anxious, while others felt passive or even relaxed. Feeling this shift as they switched from one role to the other was a revelation; it opened participants' minds to hear and imagine others' experiences, further multiplying the ways they understand tutees might feel in a session. They saw the power they held as tutors, whether real or perceived, and discussed ways to balance it and empower tutees. In just a two-minute exercise, they've felt out for themselves and internalized much of our student-centered pedagogy.

My role as Assistant Director for Writing \& Related Literacies at RISD’s Center for Arts \& Language (A\&L) is to recruit and mentor peer tutors, including planning and executing our ongoing, academic year-long tutor education program. Our staff consists of about 20 tutors, grad and undergrad, from a variety of fine art and design majors and an even wider variety of education and experience backgrounds. We meet seven or eight times throughout the school year to discuss everything from the big picture ideas that drive our pedagogy to the specifics of a common assignment we see in a lot of tutoring sessions. Throughout their tenure at A\&L, tutors attend all meetings, continuing to hone their practical and pedagogical development and share what they've learned through experience. We start each year with two retreat days-longer meetings where we can get to know each other and explore the how-to of tutoring: approaches to opening and closing a session, composition strategies to engage with tutees, balancing directive and non-directive tutoring, etc. I have adapted this program in step with our center's evolution, adding to these retreat days discussions around identity formation and discourse community multimembership. Since this training begins at the start of Fall semester, new peer tutors have to take it all in and get ready to tutor on their own within the first 
Volume 30, 2020

http://journals.sfu.ca/cjsdw

two weeks. The retreat days help give tutors the confidence and skills to take on new challenges and feel prepared for real sessions.

Hands-on experience has proven critical to this preparedness. In the same way that writing classrooms incorporate low-stakes prompts, scaffolded assignments, and multiple drafts as teaching tools, I incorporate experiential, hands-on doing for peer tutors. On the surface, they keep folks awake and engaged. On a deeper level, they appeal to different learning styles. Kinesthetic learners, for example, learn the most from applying theories, working from their own experiences, and learning from trial and error. Giving tutors the opportunity to actually practice the skills and approaches we're discussing appeals to this mode of learning. It also draws on theories of experiential learning. Alice and David Kolb (2005) describe their theory as follows: "In the process of learning one is called upon to move back and forth between opposing modes of reflection and action and feeling and thinking. ... Experiential learning is a process of constructing knowledge that involves a creative tension among the four learning modes that is responsive to contextual demands" (p. 194). In the hypnotist exercise, the physical activity gets tutors acting and feeling; the discussion afterward gets them reflecting and thinking. Or maybe it's a little blurrier than that, but it's the combination that gets tutors engaged in all four. If I give a lecture about power dynamics, or even just ask them to think about power dynamics and discuss, it remains academic, theoretical, and less relatable. Asking tutors to do in the moment produces that creative tension of acting and feeling and thinking all at once. It allows-requiresthem to come up with new knowledge instead of canned answers. So I have applied all these modes, including interactive experience, to all aspects of tutor education, from the abstract elements of interpersonal and intercultural communication to the concrete details of a specific common writing assignment.

Within and outside of our group meeting time, I provide tutors with opportunities to observe, experiment, theorize, and apply what they learn: I assign our self-published Tutor's Handbook and suggest other relevant readings; invite tutors to share accounts of both success and struggle; prompt written and spoken reflection; require new tutors to observe and shadow more experienced tutors for their first two weeks; and build activities that put the tutors in direct contact with the concepts we're discussing, with the strategies we're recommending, or with the tools we're introducing. This allows for real application and experimentation within a safe, low-stakes environment. We are together as a staff community, engaging with real materials, but we are without the pressure of a student's expectations and immediate, high stakes needs. 
Volume 30, 2020

http://journals.sfu.ca/cjsdw

I think another example will help here. This is where you're going to participate again. You'll need a partner (or create groups of three, if you've got a willing crowd). You'll also need two handouts, which you can find on our website at artsandlanguage.risd.edu/handouts. Under the Public Speaking category, download "Speech Diagrams" and "Principles \& Tips.” A timer would again be helpful. Are you ready? Let's begin.

You'll be giving a 3-minute speech to your partner or small group. To start, spend 5 minutes looking at our "Public Speaking Principles \& Tips" handout. We break it down into psychological, physical, and rhetorical considerations. I recommend focusing on the rhetorical section for the purposes of this activity. Pick just one tip, an idea you've never tried or want to improve on, to use in your presentation today.

Share your choice with the person next to you. (We hold ourselves more accountable when someone else knows about our goals, right?)

Take two minutes to brainstorm possible topics for your speech, and choose one. Keep the topic simple: how to make a peanut butter sandwich or the story of where your name comes fromsomething you know very well and could talk about in just three minutes.

Now that you know the main focus of your speech, use visual outlining to plan the content and how you'll present it. Our "Speech Diagrams" handout explains this more fully, but here's the quick version: linear outlines work well when organizing ideas for a linear text intended to be read on paper. But a speech uses different rhetorical conventions to appeal to the restrictions and possibilities of a live audience. We recommend sketching out your content visually, which helps you creatively and quickly sort and prioritize, imagining the best way to present it: as a story with an unexpected outcome, as distinct ideas that connect to a common theme, or maybe as a cycle, getting closer and closer to revealing a central point. Take five minutes to sketch out your ideas and plan the details of your speech.

Now, in your pair or small group, pick someone to present first.

Partner or group mates set a timer for three minutes while the first person presents (and try to hold them to that time limit). Take notes from the perspective of a general audience member, narrating your experience of what the speaker did, or as a critic, observing specific qualities and strategies (what you read in our Public Speaking Principles \& Tips handout). 
Volume 30, 2020

http://journals.sfu.ca/cjsdw

When the speech is done, spend two minutes sharing some feedback with the presenter-just a couple of things that worked well and one or two pieces of advice. If you know the presenter's goal from the beginning of this activity, be sure to address that in your comments.

Repeat this process for each partner or group mate.

Now, take a few minutes to freewrite about this experience. What was it like to be placed in the tutee's position? To develop and present a speech? To receive feedback and advice on that speech? How did the handouts affect your process? Did visual diagramming change the way you thought about your topic, or the way you chose to present it? Did you learn something new from the principles and tips?

If you'd like, take turns sharing these reflections with each other.

I used this activity on one of our retreat days. It exposes tutors to useful handouts in a meaningful way, allowing them to engage and apply rather than just read them. It also put tutors in the position of a tutee, the one having to do the work, feel the pressure, receive the feedback. These experiences are much more important than trying to learn everything there is to know about public speaking. At our center, peer tutoring is less about being an expert and more about having resources and strategies to share.

In the CWCA conference workshop, I didn't have time for the full activity, but I didn't reveal that no speeches would be required until after the visual diagramming step. The relief was palpable. Even just thinking they had to deliver the speech put participants in those student/tutee shoes. Perhaps some of them hadn't been in that position in a long time. At my center, A\&L, it's not just the peer tutors who do these activities; it's our professional staff as well. We're all engaged in this ongoing professional development, both introducing new ideas and refreshing existing ones.

Which was it for you, reader? Did this activity introduce new ideas? Was it familiar? The answer may have something to do with the type of tutoring your center offers. A\&L is a multiliteracy center supporting writing, public speaking, visual communication, multilingual learning, and student publishing. Like many multiliteracy centers, we grew out of a writing center, heeding the call from the New London Group's “A Pedagogy of Multiliteracies: Designing Social Futures” (2014) to support students as "creative and responsible makers of meaning" (p. 53), both through composing and in- 
Volume 30, 2020

http://journals.sfu.ca/cjsdw

terpreting multimodal texts. We had been doing multimodal work for years-discussing resume layout and thesis book design, helping students prepare for studio critique and class presentations. But we made the move to "officially" address public speaking and visual communication in stages, first employing specialists (often graduate assistants) to provide workshops and develop tutoring and training materials, then inviting small groups of interested peer tutors to participate in additional training and offer verbal- and visual-focused tutoring sessions. Within a few years, we committed to cross training all our staff.

The experiential model became increasingly important with this move. We have always hired peer tutors based on their familiarity with and demonstrated success in academic and other kinds of writing, focusing our training on developing the practice of tutoring. While I invite new applicants to submit samples of writing, public speaking, and visual communication and I ask about their experiences with each in their interviews, I cannot assume base knowledge in all these areas as I do with writing. With public speaking, for example, students always have some level of experience: from graded presentations to everyday class participation, students engage with public speaking all the time. Yet, they rarely learn how to do it in any academic way. It's usually a matter of trial and error (or sometimes trial and terror) that leads to a set of rules for what one can get away with instead of what actually works best. To cross-train folks in tutoring multiliteracies, then, I have to create a common understanding, a shared vocabulary among staff that's based on the field, that we can then share with tutees and use to respond to their work.

A lot of this content is shared in our Tutor's Handbook, a text written specifically for our student tutors. It contains chapters on our shared pedagogy and approach to tutoring, general best practices, and specific approaches to writing, public speaking, and visual communication. Having this foundation allows us to activate staff meetings as sites for reviewing, processing, and experimenting. I use that time together to give tutors first-hand experience with public speaking, visual communication, and our resources on each. Some exercises put us in the tutee role, engaging in composing processes, or the tutor role, observing, critiquing, sharing strategies, and offering feedback. Some provide both experiences, as in the previous activity.

Let's try one more exercise to practice the tutor role and try out new areas of observation and feedback - this time with visual communication. Again, this activity could be done either with a partner or in a small group (a group might be better, if this is new to you, so you have more people to 
Volume 30, 2020

http://journals.sfu.ca/cjsdw

bounce ideas off of, to learn from and be bolstered by each other). You'll need an example of something visually designed to look at together. Something not professionally designed is best: a pamphlet or poster from a campus club, or a few slides from one of your recent presentations. But you can use anything nearby: a book, a website, or even this very journal. You'll also need some blank scrap paper and writing utensils. Got it all ready? Okay, here we go.

Together, you're going to critique the graphic design of the piece you selected, based on two core principles: legibility and coherence. Legibility means ability to be read. For design, "reading" can mean a) deciphering ideas, b) following the layout, and c) literally seeing the text and visuals. Coherence is the relationships among parts, whether or not things fit together; it refers to a) relationships among elements of the design (the chosen typography, images, colors, etc.), b) between the design and the content, and c) between the aesthetic of the piece and other related work ( $a$ company's logo and its product; a single issue of a quarterly magazine; an artist's website and their studio work).

On the blank paper, draw a line down the middle. On the left side, write, "legibility." On the right side, write, "coherence." You might also jot down the definitions of each, ifyou'd like a reminder.

Now look closely at the sample you chose and collect observations on the paper, under either legibility or coherence. Noticing strengths is important, but also try to find opportunities to improve. Give yourselves a good five minutes.

Save the last minute or so to prioritize the top three issues, the things you would most likely bring up if the author/designer of this piece came in for tutoring.

How did this go? Were you surprised at how much you were able to observe in the design? Was it easy or difficult to categorize these observations-or was there overlap between them? Did you and your partner/group mates mostly agree or disagree? Why do you think that is? You may write your thoughts out first or simply discuss.

This exercise launches participants into the tutor role, having to prioritize concerns and make suggestions. I used it early on, in one of our retreat days, to introduce our core principles of visual communication, legibility and coherence. These concepts, while specific to visual design, are accessible and even transferable-easily related to other types of composing and feedback. Tutors are familiar with this practice of observing, of narrating the reader experience. We do it all the time for 
Volume 30, 2020

http://journals.sfu.ca/cjsdw

writing, inviting students to see how a reader might interpret or misinterpret a phrase or an idea. By providing a simple framework for observations, this activity applies those same skills to visual design. It gives tutors a foothold in what might otherwise be an intimidating area. Especially at an art and design school, where graphic design is an academic and professional field, it's important for tutors to feel confident in their ability to discuss visual design without claiming to be experts. We do have a few Graphic Design majors on our peer tutor staff, and they can help tutees with deeper and more technical questions. But we encourage all our tutors to notice the visual aspects of any project, to ask questions when it's clear a design move has been made or when it hasn't but maybe should be. This is a necessary skill, since, as Richard Selfe (2010) puts it, "At each step in this massively recursive communicative cycle, we are liable, these days, to encounter multimodal materials that include visual, aural, time-based (video/animation), performative, and real-time data representations" (p. 113). Students must learn how to read all these forms of communication they constantly take in and often produce; and tutors must be ready to apply their tutoring skills to any kind of media students are working with. This activity begins to stretch tutors' existing reflective and analytical skills, giving them confidence to apply them more broadly. The opportunity to discuss legibility and coherence in real samples lets tutors test out this new application of skills and new vocabulary together, within the learning space of our community.

Because this activity works to catch up newcomers and refresh returning tutors' strategies, it felt especially appropriate to share in my conference workshop. I couldn't know in advance who was coming to my session and what their knowledge of tutoring visual texts would be. This exercise and the previous one both cater to varied audiences. They allowed me to introduce public speaking and visual communication tutoring to those who had never done it while remaining focused on the purpose of training tutors for anyone who already worked at a multiliteracy center. As it turned out, everyone who attended my session fell into the former category. But I didn't expect them all to go home and turn their writing centers into multiliteracy centers; instead, I hope the experience of learning to do something totally new in such a short time convinced them of the effectiveness of hands-on activities. To that end, I also shared a list of about a dozen additional activities to spark participants' ideas and point to opportunities for more hands-on experiences in their own tutor training programs.

One thing you likely noticed across all three activities is the opportunity for reflection. This is the place where our hands-on learning crystalizes, and where we learn even more from each other. I 
Volume 30, 2020

http://journals.sfu.ca/cjsdw

often offer specific writing and discussion prompts that ask folks to process the experience, think in a more focused way, and draw connections. When there's time for larger group conversation, I like to open with something more casual: simply, "How did it go?" The answer can be just "hard," or "fun," and those answers open the door to asking more. Follow-ups, like "Why was it difficult?" or "What about it was exciting?" invite deeper insights and encourage others to bring in their own perspectives. This practice appeals to learning styles, offering different ways to process an activity. It also draws on experiential learning theory, building in opportunities to think and reflect. New tutors might be having these experiences and forming these ideas for the first time. Discussion allows them to test out what they think about it and take in others' responses as well-a rich cycle of synthesis. Experienced tutors benefit as well. They certainly take on a mentorship role in tutor education, sharing more practiced perspectives. But these activities and reflections also allow returning tutors to strengthen best practices and put words to new ones they've only intuited before. They're still building their pedagogy. We're all still building our pedagogy-we have to in order to evolve with the world of education and the world beyond it. That's why teaching and tutoring are reflective practices and why I make time for these discussions in every meeting. I always learn something new from that sharing, something beyond what I hoped everyone would get out of the activity.

In the moment, tutors show enthusiasm, excitement, gratitude, and even relief at the chance to engage hands-on, to embody the abstract ideas and strategies we're presenting more concretely. When I ask tutors for their thoughts on the entire tutor education program at the end of every year, they unanimously cite hands-on activities as most useful to their development. In Spring 2019, I asked them to comment specifically on these exercises. One tutor put it plainly: "practical examples and observations seem to serve me better than theoretical discussions." Another pointed out that "the exercises where we work in small groups with other tutors are always helpful, as we get to compare/contrast strategies." And someone who had just started tutoring the previous fall said, "As a new tutor, I found all of the [hands-on] elements very helpful for getting used to the environment, understanding what is expected of me, as well as feeling more comfortable with my co-workers!" It's gratifying to see tutors recognize their own learning styles, the concrete takeaways of staff meetings, and what it takes to acclimate tutoring. That last note, getting comfortable with fellow tutors, is especially important to me.

A wonderful side-effect of all the activities I outlined here is that they build community among our staff. Being put in awkward, vulnerable, and experimental roles opens us up and becomes a common 
Volume 30, 2020

http://journals.sfu.ca/cjsdw

experience to grow from. I don't use stand-alone ice-breaker games, because I find that these more purposeful, relevant exercises have the same effect: we laugh together at our discomfort; we hear each other's voices and get to know the personalities behind the name tags; and we listen to, encourage, and teach each other. Kolb and Kolb (2005) speak to the importance of this kind of communitybuilding to learning:

Knowledge resides not in the individual's head but in communities of practice. Learning is thus a process of becoming a member of a community of practice through legitimate peripheral participation (e.g., apprenticeship). ... [L] earning spaces extend beyond the teacher and the classroom. They include socialization into a wider community of practice that involves membership, identity formation, transitioning from novice to expert through mentorship, and experience in the activities of the practice, as well as the reproduction and development of the community of practice itself as newcomers replace old-timers. (p. 200)

In other words, learning itself is done in communities that engage in a variety of learning modes together. Tutor education is the place where we create this community and feel our membership in it. Hands-on activities build this sense of belonging and provide tutors the opportunity for "peripheral participation" in the practice of tutoring. This idea of communal learning is also central to our collective pedagogy. Tutoring itself, I believe, is about making often solitary processes more social bringing the lonely work of reading and writing and thinking into the light by sharing it with someone else. Our center is stronger when it represents the kind of learning community we hope to encourage in all of our exchanges-between tutors and tutors, tutors and professional staff, tutors and tutees.

At the conference, the feedback I received on my workshop was more anecdotal. The reflection time at the end blended with Q\&A time, and folks had lots of questions about our center and tutor education program. Maybe that's appropriate; we attend conferences to be exposed to new ideas, different models and approaches we can take back to our individual practices. The CWCA/ACCR conference, like most I've seen, invited proposals in four categories: research panel presentations, roundtable discussions, interactive workshops, and poster-style presentations. Only one of these four options is about doing. And the conference program lists 15 research panels, seven roundtables, and 10 poster presentations; only eight interactive workshops. As presenters, we're used to sharing in a lecture format, and as attendees, we're used to passively receiving or abstractly discussing. Even in the context of workshops, most that I've attended take lots of time to provide context and explain 
details, saving little time for participants to actually try things out. Perhaps there is room in conferences for more active, hands-on doing to complement the "academic" presentations. Are you planning or proposing one right now? How could you incorporate hands-on activities? How might even just one interactive aspect change the way conference-goers take in what you're sharing? And conference organizers could take up this idea, too, inviting more-or mostly, or maybe even only-interactive workshop proposals. What would a whole conference of doing feel like? Exhausting? Thrilling? We won't know until we try. Conferences are perfect places to do this kind of experimenting; they are writing center practitioners' communities of practice, the place where we share learning, not just knowledge.

Looking back, I wish I had extended the little community of practice that was my CWCA/ACCR workshop. I could have passed around a contact list or sign-up sheet for those willing to follow up with me later. It also would have been a great way to see the long-term impact of my workshop. Several participants did approach me immediately after the session or the following day to say how much they learned from it. I'm curious what that might mean to different people. Did the participants who came from centers that only work with writing leave feeling more capable of multiliteracy tutoring, as my tutors do? Or perhaps, for those who run their own tutor training programs, experiencing three hands-on activities in one hour made it feel possible to include more exercises in their own workshops and meetings. These are some of the outcomes I hoped for, but I'm sure there are more I couldn't have anticipated. And perhaps that's the challenge of a conference workshop: everyone comes from their own specific context, with their individual background, and with their particular interests and concerns. We each take away what we need to.

The biggest question for me now is: How did doing this article go for you? What was it like to move between reading on your own and activating your body in space with another person? I couldn't watch your expressions to see how engaged you were or keep an eye on your scribbling pencils to adjust the timing along the way. I couldn't overhear your discussions or ask follow-up questions. Did you even go along with the experiment? Did you skip ahead and read the intended outcomes instead? How much more or less did you gain from these choices? I can only hope that you are feeling encouraged or inspired to do something new, no matter your personal perspective or original interest in the article. Will you take a big leap, like expanding from a writing center to a multiliteracy center? Or a small step, like creating your own hands-on activity? This article-like my conference workshop and my tutor education program-is all about doing. So, what do you plan to do? 
Volume 30, 2020

http://journals.sfu.ca/cjsdw

\section{References}

Boal, A. (2002). Games for actors and non-actors (Adrian Jackson, trans.). New York, NY: Routledge.

Kolb, A.Y. and D.A. Kolb (2005). Learning styles and learning spaces: Enhancing experiential learning in higher education. Academy of Management Learning \& Education 4(2), 193-212.

Selfe, Richard (2010). Anticipating the momentum of cyborg communicative events. Multiliteracy Centers: Writing Center Work, New Media, and Multimodal Rhetoric (pp. 109-129). Creskill, NJ: Hampton Press, Inc.

The New London Group. (2014). A pedagogy of multiliteracies: Designing social futures. In S. Lee and R. Carpenter (eds.), The Routledge reader on writing centers \& new media (pp. 29-56). New York, NY: Routledge. 